American Journal of Pediatrics
2020; 6(4): $437-441$
http://www.sciencepublishinggroup.com/j/ajp
doi: 10.11648 /j.ajp.20200604.18
ISSN: $2472-0887$ (Print); ISSN: $2472-0909$ (Online)

\title{
Characteristics of Pseudomonas Aeruginosa Infection in Pediatric Patients Treated in Sanglah General Hospital Denpasar During Period February 2017 - May 2019
}

\author{
Ida Ayu Putu Purnamawati ${ }^{1, ~ *, ~ I ~ W a y a n ~ G u s t a w a n ', ~ I ~ M a d e ~ G e d e ~ D w i ~ L i n g g a ~ U t a m a ~}{ }^{1}$, \\ Ni Made Adi Tarini \\ ${ }^{1}$ Department of Child Health, Medical Faculty of Udayana University, Sanglah Hospital, Denpasar, Indonesia \\ ${ }^{2}$ Department of Clinical Microbiology, Medical Faculty of Udayana University, Sanglah Hospital, Denpasar, Indonesia
}

Email address:

dayu_purnama04@gmail.com (I. A. P. Purnamawati)

${ }^{*}$ Corresponding author

\section{To cite this article:}

Ida Ayu Putu Purnamawati, I Wayan Gustawan, I Made Gede Dwi Lingga Utama, Ni Made Adi Tarini. Characteristics of Pseudomonas Aeruginosa Infection in Pediatric Patients Treated in Sanglah General Hospital Denpasar During Period February 2017 - May 2019. American Journal of Pediatrics. Vol. 6, No. 4, 2020, pp. 437-441. doi: 10.11648/j.ajp.20200604.18

Received: October 6, 2020; Accepted: October 17, 2020; Published: October 23, 2020

\begin{abstract}
Health-care-associated infections is one of the causes of high mortality among inpatient children. Globally, prevalence nosocomial infection are 8.7\%. In Indonesia, prevalence of nosocomial infection at 2014 are 148.703 cases. One of the Gram negative pathogen that has been known can cause nosocomial infection is Pseudomonas aeruginosa. This study aims to know patient characteristic with $P$. aeruginosa infection at Sanglah Hospital. This research is descriptive study with a cross-sectional approach conducted in Sanglah Hospital, Denpasar. The study used secondary data from medical records of pediatric patients who were proven to have $P$. aeruginosa infection through microbiological examination while undergoing treatment at Sanglah hospital in the period of Februari 2017- Mei 2019. Incomplete medical record data were excluded from the study. There were 30 children with positive blood culture $P$. aeruginosa. Most of them were male (17/30), with underlying disease pneumonia (13/30), length of stay before infection 16,8 days, total length of stay 28,5 day. Most patients died (19/30). 7 patients had history positive blood culture before P. aeruginosa infection. 29 patients using peripheral intravenous line (mean 22.5 day). Most patients were sensitive to Cefepime (80\%) and resistant to Ampicilin Sulbactam (80\%). Characteristic patients with Pseudomonas aeruginosa infection mostly were male, with underlying disease pneumonia, using medical device peripheral line, and died. Most of them were sensitive to Cefepime and resistant to Ampicilin Sulbactam.
\end{abstract}

Keywords: Characteristic, Children, Health-care-Associated Infection, Pseudomonas aeruginosa Infection

\section{Introduction}

Health-care associated infections (HAIs) are a high cause of death among hospitalized children. HAIs are related to health care and occured in patients at least 72 hours after admission. Globally, the prevalence of HAIs are $8.7 \%$ [1]. In Indonesia, the incidence of HAIs in 2014 is up to 148,703 cases [2]. Data from Central Java shows that the number of HAIs in Setjonegoro Regional was increased from $0.37 \%$ to $1.48 \%$ in a year [3]. Gram negative bacteria is one of the cause of most commonly HAIs worldwide, more than $50 \%$ are caused by gram-negative bacteria. These cases are found in neonates $(25 \%)$ and children under 2 years old $(18.5 \%)$, significantly increased in intensive care unit patients (47\%) [1]. Sources of infection related to HAIs in Neonatal Intensive Care Unit
(NICU) and Pediatric Intensive Care Unit (PICU) are often due to the use of mechanical ventilation, urinary catheter, and invasive monitoring equipment [4]. According to the study of Taslim and Maskoe in 2016, the most microorganisms found in Intensive Care Unit (ICU) were gram-negative bacteria, i.e P. aeruginosa and Klebsiella pneumonia [5]. Those pathogens most often cause pneumonia, then urinary tract infection and bacteremia. Among gram-negative bacilli bacteria, $P$. aeruginosa is the leading cause of infections, especially in critical and immunocompromised patients [6].

Pseudomonas aeruginosa is gram-negative bacteria, which is mostly isolated in HAIs patients, especially in patients with pneumonia. In recently years, Multi Drug Resistant (MDR) strains was increased in frequency related to drug resistant infections, especially in HAIs and PICU patients [7-9]. Mortality, morbidity and hospital costs also increased by these 
infections. Pseudomonas aeruginosa infection is also related to high mortality due to drug resistance. Generally, the occurring of drug resistance is associated with risk factors of disease severity, such as Acute Physiological, and Chronic Health Evaluation II (APACHE II), underlying disease, intubation procedure and catheter use [12].

Pseudomonas aeruginosa is an obligate aerob gram-negative bacteria, rod-shaped from the Pseudomonadaceae family, $0.6 \times 2 \mu \mathrm{m}$ in size, can be found singly or in pairs and sometimes in short chains. It has no spores, no capsules. Pseudomonas aeruginosa has a monothricus flagella so it always move. Factors that influence the virulence of $P$. aeruginosa are flagellum, adhesion pili and non-pili, also lipopolysaccharide (LPS). Extracellular virulence factors are protease, hemolysin, exotosin A, echoenzyme $\mathrm{S}$ and pyocyanin [13].

There is no data about the characteristics of $P$. aeruginosa infection among pediatric patients in hospital wards in Bali. Therefore, we aim to know the characteristic of pediatric patients with $P$. aeruginosa who were admitted to Sanglah Hospital.

\section{Materials and Methods}

This is a cross-sectional descriptive study. Data was collected from medical records of pediatric patients aged 0-18 years who were admitted to Sanglah Hospital between February 1, 2017 and May 31, 2019.

Target population was hospitalized pediatric patients at Sanglah Hospital. Accessible population was hospitalized pediatric patients aged 0 months to 18 years at Sanglah Hospital during February 2017 to May 2019. The samples of study were pediatric patients aged 0 months to 18 years with a positive blood culture of $P$. aeruginosa during hospitalization in Sanglah Hospital Denpasar in the period of February 2017 to May 2019 and fulfilled the inclusion criteria. The criteria of inclusion were medical record data that showed positive results of $P$. aeruginosa on one side or two side blood culture. Patients was excluded if the medical record was incomplete. Samples were selected by consecutive sampling technique in the priod of February 1, 2018 to May 31, 2019.

Collected data were processed using computer. The study results were shown descriptively in tables as number (n) and percentage (\%). This study was approved by ethical committee of the Faculty of Medicine of Udayana University, Sanglah Hospital Denpasar (letter number 411/ UN. 14.2.2. VII. 14 / LP / 2019).

\section{Results}

Based on data from Clinical Microbiology Laboratory of Sanglah General Hospital, from February 1, 2017 to May 31, 2019 there were 33 pediatric patients with $P$. aeruginosa infections. There were 30 patients who met inclusion criteria, consisting of 17 male (17/30) and 13 female (13/30).

Based on their comorbidities, 13 (13/30) patients with positive blood culture of $P$. aeruginosa had pneumonia and 11 $(11 / 30)$ patients had malignancy as underlying disease.

Mean length of hospitalization before being infected with $P$. aeruginosa was 16.8 days, and the mean total length of stay was 28.5 days among patients. Outcome of patients with $P$. aeruginosa infections was 11 patients (11/30) survived and 19 patients (19/30) died. There were 7 (7/30) patients who had positive blood culture data before being infected with $P$. aeruginosa, included the history of Staphylococcus epidermidis, Staphylococcus aureus, Staphylococcus caprae, Candida parapsilosis, Achromobacter denitrificans, and Acinetobacter baumanii infections (table 1).

Table 1. Characteristic of Pseudomonas aeruginosa infection in Sanglah Hospital.

\begin{tabular}{ll}
\hline Characteristics & $\mathbf{N}=\mathbf{3 0}$ \\
\hline Sex & \\
Male & 17 \\
Female & 13 \\
Comorbid & \\
Prematurity & 3 \\
Malignancy & 11 \\
Immunodeficiency & 3 \\
Gastrointestinal Disorder & 8 \\
Congenital Heart Disease & 4 \\
Pneumonia & 13 \\
Severe Malnutrition & 5 \\
Meningitis & 4 \\
Post Surgery & 5 \\
Congenital Anomaly & 3 \\
Aplastic Anemia & 3 \\
Genitourinary Disorder & 2 \\
Autoimmune & 1 \\
Blood culture prior to Pseudomonas aeruginosa infection & \\
Staphylococcus epidermidis & 2 \\
Staphylococcus aureus & 1 \\
Staphylococcus caprae & 1 \\
Candida parapsilosis & 1 \\
Achromobacter denitrificans & 1 \\
Acinetobacter baumanii & 1 \\
No growth & 2 \\
No blood culture & 16.8 \\
Length of stay before infection (mean, in days) & 28.5 \\
Total length of stay (mean, in days) & \\
Outcome & 11 \\
Alive & 19 \\
Died & \\
\hline & \\
& \\
\hline
\end{tabular}

Based on the history of medical devices usage, there were 29 (29/30) patients with $P$. aeruginosa infection using peripheral intravenous line (in average 22.5 days), 16 (16/30) patients using nasogastric tube (in average 24.9 days), 10 (10/30) patients using ventilator (in average 5 days), 9 (9/30) patients using Continuous Positive End Pressure (CPAP) (in average 6.7 days), 10 (10/30) patients using Central Vein catheter (CVC) (in average 16.9 days) and $3(3 / 30)$ patients using urinary catheter (in average 3.3 days) (table 2 ).

Table 2. Medical devices usage in patients with Pseudomonas aeruginosa infection.

\begin{tabular}{lll}
\hline Medical devices usage & $\mathbf{N}$ & Mean (days) \\
\hline Ventilator & 10 & 5 \\
CPAP & 9 & 6.7 \\
CVC & 10 & 16.9 \\
Peripheral i.v line & 29 & 22.5 \\
Urinary catheter & 3 & 3.3 \\
Nasogastric tube & 16 & 24.9 \\
\hline
\end{tabular}

Based on the history of antibiotic use during hospitalization, most patients $P$. aeruginosa infections treated with Aminoglycoside antibiotics such as amikacin (19/30; in 
average 11.15 days), and Cephalosporin group (18/30; in average 10.8 days) (table 3 ).

Table 3. History of antibiotic use when hospitalized.

\begin{tabular}{lll}
\hline Antibiotic & N & Mean (days) \\
\hline Ampisilin & 11 & 6.7 \\
Amikacin & 19 & 11.15 \\
Gentamycin & 5 & 11.2 \\
Cefoperazone sulbactam & 11 & 4.8 \\
Cefepime & 18 & 10.8 \\
Cefixime & 6 & 9.33 \\
Cefotaxime & 1 & 12 \\
Ceftazidime & 4 & 4.75 \\
Ceftriaxone & 8 & 6 \\
Levofloxacin & 1 & 7 \\
Meropenem & 9 & 8.67 \\
Metronidazole & 2 & 13.5 \\
Piperacillin tazobactam & 1 & 6 \\
Tigecyclin & 1 & 3 \\
Vancomycin & 3 & 20.67 \\
\hline
\end{tabular}

In this study results, $P$. aeruginosa was most resistant to Ampicillin Sulbactam (24/30). Pseudomonas aeruginosa infection was most sensitive to Cefepime (24/30). The results of antibiotic sensitivity of $P$. aeruginosa infections are represented in figure 1.

\section{Discussion}

Health-care associated infections caused by $P$. aeruginosa bacteria that often causes pneumonia, urinary tract infections, and bacteremia, especially in critically-ill and immunocompromised patients [7].

In this study, there were more male than female patients with $P$. aeruginosa infections. It is consistent with Saeed and Awad [14] which showed that $54 \%$ of $P$. aeruginosa infection found in men. This is likely because men are more prone to unintentional infection wounds than women [4].

Based on comorbidity factors, $13(13 / 30)$ patients with positive blood culture $P$. aeruginosa had pneumonia and 11 $(11 / 30)$ patients had malignancy as their underlying disease. This bacteria is one of the microorganisms that causes HAIs. Inconsistent with EI Zowalaty's study [6], P. aeruginosa bacteria most often cause pneumonia. Besides, it is suggested that $P$. aeruginosa infection easily develops in critically ill and immunocompromised patients [6]. Critical illness and immunosuppressive conditions in patients facilitate the occurrence of HAIs. A Similar result showed by Choi et al [15] that bacteremia due to $P$. aeruginosa infection was originated from the respiratory tract $(39 \%, \mathrm{P}<0.0001)$ and neutropenic immunocompromised conditions $(28 \%$ of cases with $\mathrm{P}<0.0001)[15,16]$.

The length of hospital stay is related to patient's contact time with medical devices that facilitate the development of nosocomial infections such as intravenous line, urinary catheter, mechanical ventilator, central venous catheter, and nasogastric tube. In this study, patients were being treated for 16.8 days on average before being infected with $P$. aeruginosa The mean total length of stay of the patient 28.5 days, related to disease course and treatment length. This study is in accordance with Yang et al [16], which showed that the mean length of stay of patients with $P$. aeruginosa infection was
29.5 days. It was also stated that $24 \%$ ( 15 of 62 patients with $P$. aeruginosa infections) being hospitalized for more than 30 days [16].

Health-care associated infections can cause high mortality rates in hospitals especially in patients with immunodeficiency. In this study, the outcome of patients who died with $P$. aeruginosa was $63.3 \%(19 / 30)$. This is related to the resistance of $P$. aeruginosa to antibiotics and the maturity of the immune system in children. Immaturity of the immune system can delay diagnosis due to less specific symptoms [4]. Pseudomonas aeruginosa infection is also associated with high mortality due to drug resistance, especially in patients with neutropenia [17]. Righi et al [17] found $60 \%$ (18 out of 30 studies) infections were associated with $P$. aeruginosa resistance to Carbapenem with mortality rate of $33-71 \%$. The results showed increased mortality in carbapenem-resistant patients with Odds Ratio (OR) 4.89 [12]. Some risk factors related to drug resistance were the mortality score of APACHE II, underlying disease, intubate procedure and catheter use [12].

Peripheral intravenous line placement and CVC is one of the causes of bacteremia. Potential risk factors for bacteremia are hygiene, dressing, humidity at the puncture site, and microorganism colonization in adjacent area [18]. In our study, $29(29 / 30)$ patients had a history of using peripheral intravenous line with mean length of use for 22.5 days and 10 (10/30) patients had CVC line placement (with average use for 16.9 days). It is consistent with study of Tumberello et al [19], which showed that $24.2 \%$ of patients with $P$. aeruginosa infection had been using CVC. Patients using CVC have 64 times the risk of bacteremia compared to peripheral intravenous line. The use of CVC for more than 10 days can facilitate colonization of microorganism and spread the infection [18]. In our study, there were $3(3 / 30)$ patients with a record of urinary catheter use (3.33 days in average) (table 2).

Our results shows that there were $10(10 / 30)$ patients on ventilator (for average 5 days). It is consistent with the research of Tumberello et al [19] that $21 \%$ of patients with $P$. aeruginosa infections had been on mechanical ventilation. We found 9 patients with a history of CPAP use (6.77 days in average) in our study. Yang et al [16], showed a consistent results that MDR infection of $P$. aeruginosa was more frequent in the intensive care unit patients. Odds ratio for the risk of multidrug resistant of $P$. aeruginosa bacteremia in intensive care unit was $6.8 ; \mathrm{P}=0.023$ [16]. The Tumberello et al [19] found $20.1 \%$ of patients with $P$. aeruginosa infections was being been treated in intensive care for 1 month.

Based on the use of antibiotic during hospitalized, most patients with $P$. aeruginosa infections were treated using Aminoglycoside such as Amikacin (19/30; mean 11.15 days), and Cephalosporin-group (18/30; mean 10.8 days). It is in accordance with sensitivity pattern of this bacteria. Yang et al [16] found that broad-spectrum Cephalosporin was used in $22 \%$ patients with $P$. aeruginosa infection. Yang's study also suggested that in the cases of antibiotic resistance of $P$. aeruginosa often associated with the use of broad-spectrum antibiotic, Cephalosporin, for 1 month (OR 6.0; 95\% CI $1.2-31.1 ; \mathrm{p}=0.033$ ) [16]. Previous use of antibiotics had an effect on colonization that intrinsically resistant to $P$. aeruginosa. This bacteria also has the ability to quickly 
become resistant during treatment with antipseudomonas [19].

In our study, $P$. aeruginosa was most sensitive to Cefepime (80\%), followed by Gentamicin (76.67\%), Amikacin $(73.33 \%)$ and Ceftazidime (73.33\%) (figure 1). It is consistent with a study by Saeed and Awad [14], that the P. aeruginosa bacteria that were isolated from infection wounds, ear swabs and urine had a susceptibility to third-generation Cephalosporin, Ceftazidime, as much as $91 \%$ [14]. This may be due to a similar mechanism of action between Cephalosporin and penicillin. Cephalosporin binds to a penicillin-binding-protein which acts as a drug receptor in bacteria, then inhibits cell wall synthesis by inhibiting peptidoglycan transpeptidation and activates autolytic enzymes in cell walls which result in bacterial death. In addition, the third-generation Cephalosporin is able to reach central nervous system and sufficiently concentrated in spinal fluid to overcome gram-negative bacillary meningitis [20]. In this study, it was said that improper antimicrobial selection can increase mortality compared to susceptible antimicrobials. In multiple logistic regression analysis, it is identified that improper antimicrobials becomes a predictor of mortality in hospital. Data in this study also show that a combination of antimicrobials becomes more appropriate compared to monotherapy. Eventually, Fluoroquinolone is tend related to inappropriate initial therapy, while Cefepime and Ceftazidime are statistically significant in related to appropriate therapy. Patients with appropriate antimicrobial therapy in statistically significant were patients who received Cefepime and Ceftazidime $(61.3 \%$ and $15.7 \% ; \quad \mathrm{P}=0.009$ and $\mathrm{P}=0.009$ respectively) [20].

In our study, $P$. aeruginosa was most resistant to Ampicillin Sulbactam $(80 \%)$, followed by Trimetoprim sulfametazaxole (66.67\%), and Cefazolin (66.67\%) (figure 1). Previous study by Gasink et al [21] showed a different result that $P$. aeruginosa was resistant to Fluoroquinolone with an increased prevalence of resistency from $15 \%$ in 1991 to $41 \%$ in $2000(\mathrm{p}<0.001)$ [21].

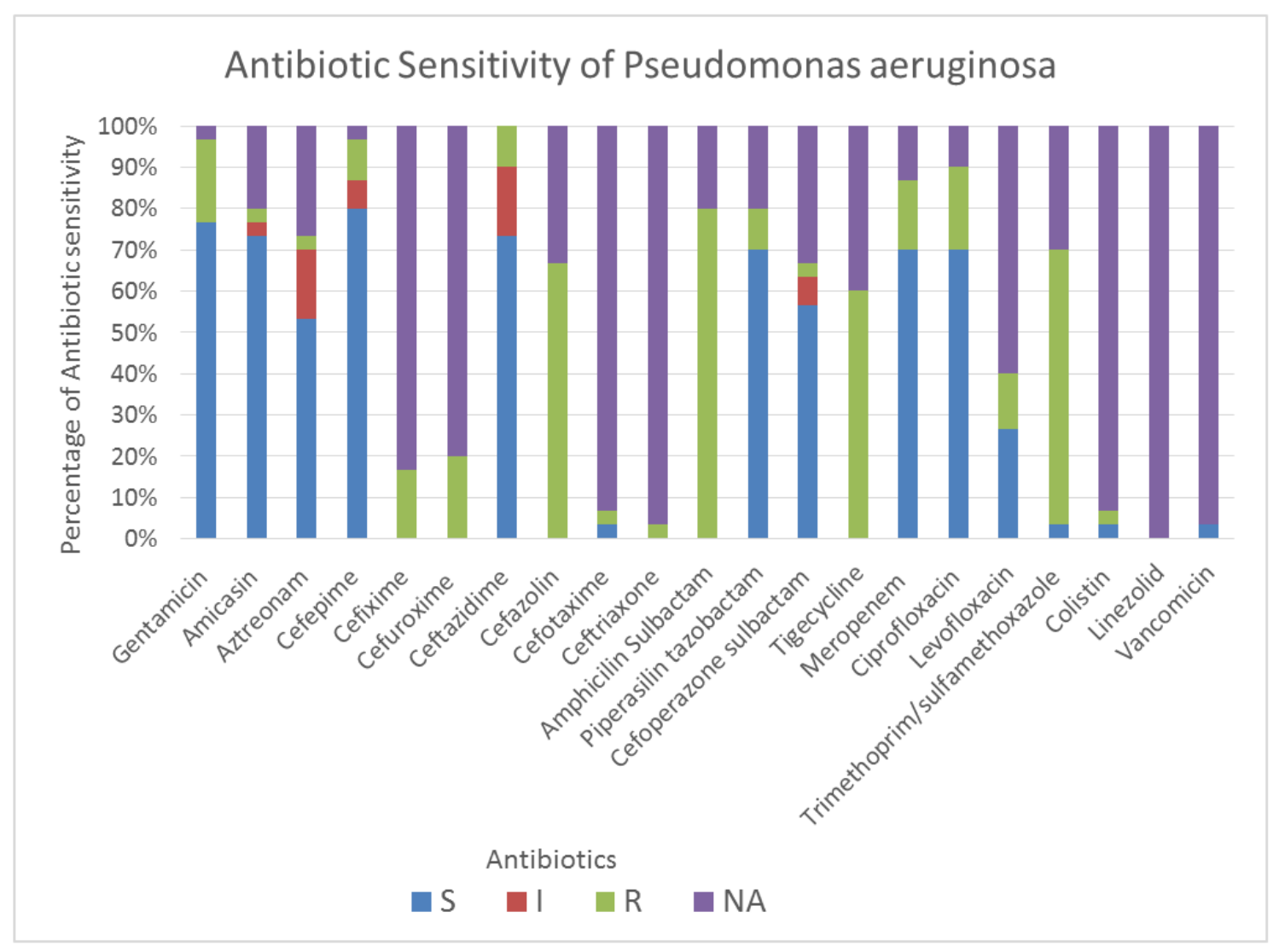

S: sensitive, I: intermediate, R: resistant; NA: not available

Figure 1. Antibiotic sensitivity pattern of Pseudomonas aeruginosa.

\section{Conclusions}

Characteristics of pediatric patients with $P$. aeruginosa infection in RSUP Sanglah were mostly male, with pneumonia as comorbid, using peripheral intravenous line and mostly died. Most cases were sensitive to Cefepime and resistant to Ampicillin Sulbactam.

Control of infection in hospital can significantly decrease nosocomial infection rate caused by $P$. aeruginosa, which will result in the lower use of broad spectrum antibiotics and drug resistance. Periodic evaluation of rational antibiotic use in a hospital with an antibiotic restriction policy is needed.

Descriptive design and the use of medical record data become limitation of this study. Our study did not analyze the related events which can affected $P$. aeruginosa infection. In addition, we did not sure whether the blood cultures sampling and delivering was done in appropriate ways. Since this study used a retrospective data, false positive results can be occured. A further research is needed by using a prospective design to overcome our limitations. 


\section{Disclosure}

All the authors do not have any possible conflicts of interest.

\section{Acknowledgements}

Special thanks to Laboratory Clinical Microbiology of Sanglah Hospital for providing the research data.

\section{References}

[1] Bezadnia S, Davoudi A, Rezai M, Ahangarkani F. Nosocomial infections in Pediatric Population and Antibiotic Resistance of the Causative Organisme in North Iran. Iran Red Crescent Medical Journal. Vol 16, No. 2, 2014, pp. 145-62.

[2] Nugraheni, R. Suhartono. and Winarni, S. Infeksi Nosokomial di RSUD Setjonegoro Kabupaten Wonosobo. Media Kesehatan Masyarakat Indonesia. Vol. 11, No. 1, 2012, pp. 94-100.

[3] Noer, SF. Pola Bakteri Dan Resistensinya Terhadap Antibiotik Yang Ditemukan Pada Air Dan Udara Ruang Instalasi Rawat Khusus RSUP Dr. Wahidin Sudirohusodo Makassar. Majalah Farmasi dan Farmakologi. Vol 16, No. 2, 2012, pp. 73-78.

[4] Asi MH, Nateghian A. Epidemiology of nosocomial infections in a pediatric intensive care unit (PICU). Iranian Journal of Clinical Infectious Diseases. Vol. 4, No. 2, 2009, pp. 83-86.

[5] Taslim E, Maskoen TT. Pola Kuman Terbanyak Sebagai Agen Penyebab Infeksi di Intensive Care Unit pada Beberapa Rumah Sakit di Indonesia. Anesthesia \& Critical Care. Vol. 34, 2016, pp. 56-62.

[6] El Zowalaty ME, Al Thani AA, Webster TJ, El Zowalaty AE, Schweizer HP, Nasrallah GK, et al. Pseudomonas aeruginosa: arsenal of resistance mechanisms, decades of changing resistance profiles, and future antimicrobial therapies. Future Microbiology. Vol. 10, No. 10, 2015, pp. 1683-706. Access from: http://dx.doi.org/10.2217/fmb.15.48.

[7] Bayani M, Siadati S, Rajabnia R, Taher AA. Drug Resistance of Pseudomonas aeruginosa and Enterobacter cloacae Isolated from ICU, Babol, Northern Iran. International Journal of Molecular Celular Medicine. Vol. 2, 2013, pp. 204-209.

[8] Falagas ME, Sideri G, Vouloumanou EK, Papadatos JH, Kafetzis DA Intravenous colistimethate (colistin) use in critically ill children without cystic fibrosis. Pediatric Infectious Disease Journal, Vol. 28, 2009, pp. 123-127.

[9] Folgori L, Livadiotti S, Carletti M, Bielicki J, Pontrelli G, Ciofi Degli Atti ML, et al. Epidemiology and clinical outcomes of multidrug-resistant, gram-negative bloodstream infections in a European tertiary pediatric hospital during a 12-month period. Pediatric Infectious Disease Journal. Vol. 33, 2014, pp. 929 932.

[10] Zhang Q, Smith JC, Zhu Q, Guo Z, MacDonald NE. A five-year review of Pseudomonas aeruginosa bacteremia in children hospitalized at a single center in southern China. International Journal Infectious Disease, Vol. 16, 2012, pp. 628-632.

[11] PengY, Bi J, Shi J, Li Y, Ye X, Chen X, et al. Multidrug-resistant Pseudomonas aeruginosa infections pose growing threat to healthcare-associated infection control in the hospitals of Southern China: a case-control surveillance study. American Journal of Infection Control, Vol. 42, 2014, pp. $1308-1311$.

[12] Basseti M, Vena A, Croxatto A, Righi E, Guery B. How to Manage Pseudomonas aeruginosa infections. Drugs in Context Vol. 7, 2018, pp. 1-18.

[13] Mayasari E. Pseudomonas aeruginosa; Karakteristik, Infeksi dan Penanganan. USU Repository. 2006.

[14] Saeed AH, Awad AA. Susceptibility of Pseudomonas aeruginosa to third generation Cephalosporins. Journal of Science and Technology, Vol. 10, No. 2, 2009, pp. 195-200.

[15] Choi Y, Paik JH, Kim JH, Han SB, Durey A. Clinical predictors of Pseudomonas aeruginosa Bacteremia in emergency department. Emergency medicine international. 2018, pp. 1-5. Access from: DOI: 10.1155/2018/7581036.

[16] Yang MA, Lee J, Choi EH, Lee HJ. Pseudomonas aeruginosa bacteremia in children over ten consecutive years: analysis of clinical characteristics, risk factor of multi-drug resistance and clinical outcomes. Journal of Korean Medical Science. Vo. 26, 2011, pp. 612-18. Access from: DOI: 10.3346/jkms.2011.26.5.612.

[17] Righi E, Peri AM, Harris PN, Wailan AM, Liborio M, Lane $\mathrm{SW}$, et al. Global prevalence of carbapenem resistance in neutropenic patients and association with mortality and carbapenem use: systematic review and metaanalysis. Journal of Antimicrobial Chemotherapy. Vol. 72, No. 3, 2017, pp. 668-77. Access from: DOI: 10.1093/jac/dkw459.

[18] Gahlot R, Nigam C, Kumar V, Yadav G, Anupurba S. Catheter-related bloodstream infections. International Journal of Critical Illness and Injury Science. Vol. 4, 2014, pp. 162-8. Access from: DOI: 10.4103/2229-5151.134184.

[19] Tumbarello M, Repetto E, Trecarichi EM, Bernardini C, De Pascale G, Parisini A, dkk. Multidrug-resistant Pseudomonas aeruginosa bloodstreaminfections: risk factors and mortality. Epidemiology Infectious disease. Vol. 139, 2011, pp. 1740-9. Access from: DOI: 10.1017/S0950268810003055.

[20] Micek ST, Llyod AE, Ritchie DJ, Reichley RM, Fraser VJ, Kollef MH. Pseudomonas aeruginosa Bloodstream Infection: Importance of Appropriate Initial Antimicrobial Treatment. Antimicrobial, agents and chemotherapy. Vol. 49, No. 4, 2005, pp. 1306-11.

[21] Gasink LB, Fishman NO, Weiner MG, Nachamkin I, Bilker WB, Lautenbach E. Fluoroquinolone-resistant Pseudomonas aeruginosa assessment of risk factors and clinical impact. The American Journal of Medicine. Vol. 119, 2006, pp. 526. e19-25. 